

\title{
Editorial
}

\section{Twelve months on}

\author{
Malcolm Boyle PhD'
}

\author{
Affiliation: \\ ${ }^{1}$ Monash University, Victoria
}

Twelve months ago the Australasian Journal of Paramedicine (AJP) published the first issue in the resurrection of the former Journal of Emergency Primary Health Care, as an international prehospital care open source journal, supported by Paramedics Australasia (PA).

In the last 12 months many things have happened, the journal has published at least four articles in each of the main issues and has published the PA conference abstracts as supplementary issues. The appointment of an editorial assistant has made the management of the journal more efficient. We are still receiving regular manuscripts for consideration and will continue with the four issues per year plus special issues for conference abstracts. The journal now has a logo which will be displayed on the journal home page and articles. Over the last 12 months paramedics have been voted as the most trusted profession in Australia and New Zealand, again, yet paramedics are still not registered, what else do we need to do?

From this issue the journal will have its own dedicated site which will be totally managed by the AJP with no branding other than PA and the AJP. I would like to thank Monash University and Edith Cowan University for hosting the journal over the past years.

This issue concentrates mainly on studies involving students during their education process. The article by Khatiban and colleagues looks at the job satisfaction level of Iranian emergency medical service (EMS) staff, including exposure to violence in the workplace as part of the satisfaction with the workplace (1). The article by Johnson and colleagues looks at the communication between students, especially interprofessionally, during scenario based work. (2). The article by Lim and colleagues investigates the use of students in research projects and the potential use in the curriculum (3). O'Meara and colleagues investigate the quality and importance of clinical placements for undergraduate paramedic students (4). The study by Ross and colleagues looks at undergraduate paramedic student perceptions of their interpersonal communication skills (5).

Dr Mal Boyle

Editor

Australasian Journal of Paramedicine

\section{References}

1. Khatiban M, Hosseini S, Bikmoradi A, Roshanaei G, Karampouria A. Job satisfaction level and its main determinants among Iranian Emergency Medical Service's personnel: A population-based survey. Australasian Journal of Paramedicine 2014;11(4).

2. Johnston T, MacQuarrie A, Rae J. Bridging the gap: Reflections on teaching interprofessional communication to undergraduate paramedic and nursing students. Australasian Journal of Paramedicine 2014;11(4).

3. Lim D, Grant-Wakefield C, Tippett V. Engaging paramedic students in research: A case report. Australasian Journal of Paramedicine 2014;11(4).

4. O'Meara P, Hickson H, Huggins $\mathrm{H}$. Starting the conversation: What are the issues for paramedic student clinical education? Australasian Journal of Paramedicine 2014;11(4).

5. Ross L, Boyle M, Williams B, Fielder C, Veenstra R. Perceptions of student paramedic interpersonal communication competence: A cross-sectional study. Australasian Journal of Paramedicine 2014;11(4). 